\title{
Willingness to Pay for Shrimp with Homegrown by Heroes, Community-Supported Fishery, Best Aquaculture Practices, or Local Attributes
}

\author{
Graham Soley ${ }^{1 \star * *}$, Wuyang $\mathrm{Hu}^{2}$ and Michael Vassalos ${ }^{3}$ \\ ${ }^{1}$ U.S. Department of Agriculture, Foreign Agricultural Service, Washington, D.C., USA, ${ }^{2}$ Department of Agricultural, \\ Environmental, and Development Economics, The Ohio State University, Columbus, Ohio, USA and ${ }^{3}$ Department of \\ Agricultural Sciences, Clemson University, Clemson, South Carolina, USA \\ ${ }^{*}$ Corresponding author. Email: graham.soley@fas.usda.gov \\ ${ }^{*}$ This paper is not part of G. Soley's official duties at the U.S. Department of Agriculture, Foreign Agricultural Service. The \\ piece was prepared independently from the department, and the authors' views do not represent those of the U.S. Department \\ of Agriculture, Foreign Agricultural Service.
}

\begin{abstract}
With the seafood food market endowed with various attributes, consumers may prefer certain certifications over others. By surveying a diverse sample of respondents, this study examines consumer preference for farmraised shrimp in Kentucky and South Carolina. Respondents' assessment of certain seafood labels is evaluated using a stated preference survey. Willingness-to-pay (WTP) estimates and various product profiles are generated. Consistent with previous studies, a strong preference for fresh and "local" was found. Furthermore, Homegrown by Heroes was highly valued among participants, as well as Best Aquaculture Practices. Based on WTP estimates for these attributes, marketing and policy recommendations are discussed.
\end{abstract}

Keywords: Best Aquaculture Practices; Community-Supported Fishery; Home Grown by Heroes; willingness to pay

JEL Classification: Q13

\section{Introduction}

Food labels can convey several credence attributes related to food production practices (e.g., origin, environmental certifications, etc.), striving to make information more available and transparent for consumers and potentially improving the market share of a product (Bonroy and Constantatos, 2014). Product adoption and ultimate success depend on consumers' acceptance, perceptions, and willingness to pay (WTP) for what the labels convey (Caswell and Mojduszka, 1996). With an increasingly competitive and global marketplace, suppliers may find it profitable to adopt certain labeling strategies to differentiate their food products. By evaluating a diverse sample of U.S. consumers and their assessments of selected seafood labels, this study contributes to the literature by investigating whether certain labeling schemes, some of which have not been examined previously, receive significant consumer support.

Seafood is the most widely traded food commodity in the world, with most consumption in developed countries supplied from developing nations (Asche et al., 2015; Jacquet et al., 2010). To illustrate, by value approximately $80 \%$ of U.S. seafood consumption is imported (Lowther and Liddel, 2015). Total U.S. import values of fishery products were $\$ 35.9$ billion in 2014, an increase of $8 \%$ over the previous year (Lowther and Liddel, 2015). Considering this extent of trade and competition, there is also a strong incentive to differentiate one's product. Labeling specific characteristics and segmenting the market is a popular strategy to accomplish this goal.

(C) The Author(s) 2019. This is an Open Access article, distributed under the terms of the Creative Commons Attribution licence (http:// creativecommons.org/licenses/by/4.0/), which permits unrestricted re-use, distribution, and reproduction in any medium, provided the original work is properly cited. 
Using shrimp as the focus product, the present study contributes to the literature by investigating consumers' preferences for several seafood labeling options, including some that, to the best of our knowledge, have not been previously examined. Specifically, the following labels are evaluated: Fresh (Never Frozen) or Previously Frozen (representing the "product form"), Best Aquaculture Practices (BAP), Kentucky Proud or Certified South Carolina Seafood (representing "local"), a hypothetical "Product of Community-Supported Fishery" (CSF), and Homegrown by Heroes (HBH). No study has evaluated how $\mathrm{HBH}$ or a CSF-derived product may affect consumer choices, and little research has been devoted to aquaculture ecolabels like BAP. Preferences are assessed through WTP estimates. Furthermore, various consumer profiles are generated from the choice model results suggesting vastly different WTP according to consumer characteristics.

Our empirical analysis focuses on consumers' preferences for farm-raised shrimp among Kentucky and South Carolina residents. A number of reasons explain these specific choices. Shrimp is of interest from a demand perspective, with consumption higher than any other seafood in the United States (Lowther and Liddel, 2015). Second, Kentucky and South Carolina are both southeastern states with a significant number of shrimp farms. The U.S. Department of Agriculture, National Agricultural Statistics Service's (USDA-NASS) most recent Census of Aquaculture discloses an array of seafood farms for South Carolina, with shellfish ${ }^{1}$ such as shrimp providing most of the state's aquaculture production (USDA-NASS, 2014). Freshwater aquaculture is notable for Kentucky, with the inland state having the most freshwater shrimp farms at the time of the census (USDA-NASS, 2014). To make the products in the two states more comparable, this analysis does not distinguish between freshwater and saltwater shrimp, and respondents were told to evaluate freshwater shrimp. Third, Kentucky and South Carolina are among several states that have devoted significant research to the viability and production of shrimp aquaculture. Last, with Kentucky having no direct access to the sea and South Carolina located on the coast, these contrasting locations also provide a respectable foreground for studying demand.

\section{Background}

Evaluating recent perceptions of shrimp products can disclose current and future trends in consumption, as market research is important in assessing consumer preferences. Although the literature pertaining to seafood is not as extensive as other food products, research devoted to consumer perceptions and attitudes has progressed in the past 25 years (e.g., Anderson and Bettencourt, 1993; Charles and Boude, 2001; Davidson et al., 2012; Hanson, Herrmann, and Dunn, 1995; Holland and Wessells, 1998; Jaffry et al., 2004; Johnston et al., 2001; O'Dierno et al., 2006; Quagrainie, Hart, and Brown, 2008; Ratliff, Vassalos, and Hu, 2018; Roheim, Sudhakaran, and Durham, 2012; Rudd, Pelletier, and Tyedmers, 2011; Wessells, Kline, and Anderson, 1996; Whitmarsh and Palmieri, 2009). Carlucci et al. (2015) provide a detailed literature review of recent seafood preference studies in the United States and Europe. The research highlights that quality, safety, and price are important factors for consumers' seafood purchasing decisions. However, when compared with consumers of other animal proteins, seafood consumers may have unique preferences. For instance, although research indicates that consumers will pay premiums for U.S. meat products (e.g., Lim et al., 2013; Loureiro and Umberger, 2003), this has not always been the case for seafood. Jaffry et al. (2004) found that consumers prefer domestically caught to imported seafood for all the products they examined. However, Kuchler, Krissoff, and Harvey (2010) found no statistically significant impact of country-of-origin labeling on U.S. household seafood consumption. Furthermore, Poerwanto (2011) found strong consumer heterogeneity in participants' preference for "previously frozen" and "never frozen" seafood, and Davidson et al. (2012) also supported that view. The aforementioned discussion indicates the need for further research related to consumer preferences

\footnotetext{
${ }^{1}$ According to the Cambridge Dictionary, a shellfish is "an animal that lives in water and has a shell. Lobsters, crabs, shrimp, mussels, and oysters are all shellfish commonly eaten as food."
} 
for seafood products, assessing both "traditional" (i.e., fresh vs. frozen) and emerging credence attributes.

Following the release of the National Ocean and Atmospheric Administration's Aquaculture Policy in June 2011, sustainable aquaculture has been strongly and globally advocated (Aquaculture Stewardship Council, 2016). The BAP is one organization certifying aquaculture production on an international scale. BAP defines the following elements as most important to responsible aquaculture: environmental responsibility, social responsibility, food safety, animal welfare, and traceability (Best Aquaculture Practices Certification, 2016). Through certifying finfish, crustaceans, and mussels, the third-party certification system outlines the elements of responsible aquaculture. BAP's ecolabel appears on frozen and prepared seafood packages. Keeping in mind that aquaculture is pivotal to increasing seafood supply for food security, the Global Aquaculture Alliance (GAA) advocates responsible and sustainable aquaculture by working with nongovernmental organizations, industry, governments, and academia to meet these challenges (GAA, 2016). As of 2016, BAP certified 40 operations in the United States, of which 12 processed shrimp products (BAP, 2016). However, none originated specifically from Kentucky or South Carolina.

Food systems focusing on direct marketing (e.g., farmers' markets, community-supported agriculture [CSA], etc.) have sprung up across the United States as states' agriculture departments promote "local" producers' products (i.e., Kentucky State Proud, Certified South Carolina Seafood, etc.; Low et al., 2015). "Local" food products are intended to represent transparency, traceability, and short supply chains (Marsden, Banks, and Bristow, 2000). Similarly, preference for origin labeling, especially "local," has made recent strides in the seafood sector. However, there is a lack of research in consumers" perception of "local" seafood, and the definition is somewhat obscure (Adams and Adams, 2008; Fonner and Sylvia, 2014; Smith and MacKinnon, 2007).

For seafood, consumers may define "local" by port, region, product traveling 175 miles inland, or even country (Brinson, Lee, and Rountree, 2011; Merritt et al., 2018; Nganje, Hughner, and Lee, 2011). For example, the Port Clyde CSF in Maine distributes product to New York and promotes itself as "local" (Brinson, Lee, and Rountree, 2011). For the present study, we utilize the "Kentucky State Proud" and "Certified South Carolina Seafood" labels to represent the term. Both labels allow products grown/harvested or processed in the state to be considered local. As a result, "local" is defined as a product sourced from the survey participants' state of residence. This gives the term a more tangible depiction and examines how consumers value state-sourced shrimp.

A popular marketing model also placing emphasis on origin and traceability is the CSF, which is designed after the CSA, a food system that has gained extensive support across the United States (Andreatta, Nash, and Martin, 2011). Just as CSA "shares" are allocated, CSF consumers provide up-front payments in exchange for scheduled seafood deliveries, and both consumers and producers share the risk of production (Brinson, Lee, and Rountree, 2011). Although this analysis examines only farmed shrimp products, the "Product of CSF" label is utilized as an attribute. When considering demand markets outside of the CSF itself, CSF producers may opt to sell excess product (leftover from allocated shares) to indirect markets such as retail. Within these retail markets, the CSF label may be applied to represent the business model.

Furthermore, as a supplement to operations, a group of producers could pool their products into one entity (like a cooperative) and sell to an array of indirect outlets. For example, the Yankee Fishermen's Cooperative in Seabrook, New Hampshire, operated and sold product outside its own shrimp CSF (Brinson, Lee, and Rountree, 2011). In theory, producers may decrease risk by expanding and diversifying their markets. However, in comparison with other agricultural enterprises, it may be difficult to assimilate seafood products. Nevertheless, there have been no studies examining how consumers would evaluate such a label.

Lastly, another label not examined in the literature is $\mathrm{HBH}$. The $\mathrm{HBH}$ program was founded by the Kentucky Department of Agriculture (KDA) and distributed nationally through the Farmer Veteran Coalition (KDA, 2015). The KDA was determined to add value to veterans' farm products (KDA, 2015). Kentucky's former commissioner of agriculture, James Comer, launched the HBH 
program in January 2013. The program now includes more than 250 members in 43 states, as the label serves to inform consumers that products were produced by veterans. The label is currently available to farmers, ranchers, fishers, and value-added producers of all branches and eras of military service (Farmer Veteran Coalition, 2015). Thus far, the label has been applied to a diverse array of food and beverage products, reiterating its versatility.

The $\mathrm{HBH}$ program was established under the belief that agriculture is a sound occupation for veterans. When returning from deployment overseas to uncertain job prospects, agricultural programs can exist as a viable option for employment. Moreover, veterans have the opportunity to register for mentoring programs on farms and the choice to enroll as a "Beginning Farmer" (eligible for privileges in USDA programs and loans).

The label quickly gained support from other states. South Carolina Agriculture Commissioner Hugh Weathers stirringly endorsed the label's potential (radio interview) by discussing veterans' natural fit in such occupations (South Carolina Department of Agriculture, 2015). These discussions are consistent with the establishment of the USDA's Military Veterans Agricultural (MVA) Liaison, which was instituted in the 2014 Agricultural Act. The MVA Liaison "coordinates USDA leadership across the Department to provide information, resources, and support for active duty military and veterans interested in agriculture" (USDA, 2014). The MVA Liaison also facilitates relations between the USDA, other government agencies, and nonprofits to expand opportunities for veteran employment. In short, the $\mathrm{HBH}$ label provides consumers a mechanism to signify support for veterans' service. Yet, no study, to the best of our knowledge, has investigated consumer preference for such a label. Our study fills this void.

\section{Methods}

An online survey instrument was utilized as the main data collection tool. The survey was distributed by Qualtrics to primary shoppers in Kentucky and South Carolina. As mentioned previously, fielding the survey in both states allowed for analyzing differences such as geographic characteristics. In regard to seafood products, this is pivotal considering that a participant's proximity to the seacoast may affect preference (Zhou, Hu, and Huang, 2016). The finalized survey questionnaire was designed and distributed in the month of February 2016.

Prior to its distribution, the survey instrument was pilot tested with two types of focus groups for suggestions on improvement. The first group included three experts in both business and research areas. Their role was to ensure that the survey instrument described situations that were realistic and scientifically sound. The second group consisted of eight households' primary grocery shopper (adults 18 and over). Two focus groups of this type were conducted in each state, respectively.

The survey questionnaire included three sections. The first section asked consumers about general seafood awareness and food shopping behaviors. The second section included a discrete choice experiment (DCE) to elicit consumers' preference and associated WTP for the labels examined. The survey concluded with questions regarding sociodemographic information, including gender, age, household size, education, and annual household income (before tax).

The stated preference approach is preferred over scanner data, because several characteristics considered were not available in the market (e.g., "Product of CSF"). Among stated preference methods, DCEs have performed well in comparison to several other contingent valuation methods (Adamowicz et al., 1998). The DCE method is useful in producing reliable marginal values associated with each product attribute (List, Sinha, and Taylor, 2006; Lusk and Fox, 2003). We used the cheap talk technique to control for hypothetical bias as laid out by Silva et al. (2011), which shows that marginal WTP measures calculated in DCEs with cheap talk were close to those estimated from the actual field using real choice data.

In the DCE design for farm-raised shrimp, the product attributes varied according to the following six characteristics: (a) product form (i.e., fresh or frozen) (b) BAP (c) local (d) product of CSF (e) $\mathrm{HBH}$, and (f) price. Table 1 presents these attributes and their levels. Prices for 
Table 1. Product attributes used in discrete choice experiment

\begin{tabular}{|c|c|c|c|c|c|c|}
\hline Attribute & Product Form & Local & BAP & CSF & $\mathrm{HBH}$ & $\begin{array}{l}\text { Price per } \\
\text { Pound }(\$)\end{array}$ \\
\hline Level & 2 & 2 & 2 & 2 & 2 & 4 \\
\hline Description & $\begin{array}{l}\text { Previously } \\
\text { Frozen, Fresh } \\
\text { (Never Frozen) }\end{array}$ & Present, absent & Present, absent & Present, absent & Present, absent & $\begin{array}{c}9.99,12.99 \\
15.99,18.99\end{array}$ \\
\hline
\end{tabular}

Note: BAP, Best Aquaculture Practices; CSF, Community-Supported Fishery; HBH, Homegrown by Heroes.

\begin{tabular}{|c|c|c|}
\hline Option A & Option B & \\
\hline FERS & PRESH & $\begin{array}{c}\text { I will not } \\
\text { choose Option } \\
\text { A or B }\end{array}$ \\
\hline$\$ 12.99 /$ LB & $\$ 9.99 / \mathrm{LB}$ & \\
\hline$r$ & $r$ & $r$ \\
\hline
\end{tabular}

Figure 1. Example of a sample choice card in the choice experiment.

farm-raised shrimp resulted in a range between [\$9.99, \$18.99] per pound. This range was determined by obtaining retail prices at the time of the survey. Then, following $\mathrm{Hu}$, Woods, and Bastin (2009), the market price range was expanded by one standard deviation on both ends. This sought to accommodate the possible values associated with the attributes considered.

Given the attributes and their corresponding levels, we conducted a fractional factorial design through SAS achieving $D$-efficient score of $100 \%$. This generated eight choice situations. Each choice situation (choice card) contains two products side by side and a third option of not choosing either of the first two products. Louviere, Hensher, and Swait (2000) suggest one ("I choose not to purchase either option") choice along with the other two profiles, to evade a conditional situation and approximate "true" demand. To avoid an order effect, the sequence of choice options was randomized (Carson et al., 1994).

A depiction of the choice card is presented in Figure 1. For BAP, CSF, and HBH (all of which are somewhat unfamiliar attributes), a brief presentation was accessible before participants proceeded with the DCE. Appendix A presents the attribute information included in the questionnaire.

To gauge whether respondents read and understood the information presented (for each of the three attributes), a participant was presented a statement, and asked to indicate whether the statement was true or false based on the information presented earlier. Participants could retract and revisit the web page providing information on the attributes. For each attribute, shown randomly, either a true or a false statement would appear. In other words, the authors prepared both a true and a false statement for each attribute; however, each participant was randomly presented one for each attribute. Appendix B displays the statements. These statements were created after intensive discussion with experts and general consumers. Whether participants answered each of these questions correctly was used to model their choices. A total of $63 \%$ and $65 \%$ of the respondents answered all three questions correctly in Kentucky and South Carolina, respectively.

Participants were then instructed to proceed with a choice card and select one of the three options provided. Respondents were informed that all other product characteristics were identical for each situation (except the attributes explicitly presented). Finally, participants were reminded not to compare across situations as if they were shopping in a grocery store. Appendix C presents an abbreviated version of the survey instrument. 
Table 2. Sample and population sociodemographic statistics

\begin{tabular}{|c|c|c|c|c|}
\hline & \multicolumn{2}{|c|}{ Kentucky } & \multicolumn{2}{|c|}{ South Carolina } \\
\hline & Sample & State & Sample & State \\
\hline Number & 505 & $4,413,457$ & 506 & $4,727,273$ \\
\hline \multicolumn{5}{|l|}{ Gender (\%) } \\
\hline Female & 66.5 & 50.8 & 71.1 & 51.4 \\
\hline \multicolumn{5}{|l|}{ Age (\%) } \\
\hline $18-25$ & 13.9 & 13.6 & 16.2 & 14 \\
\hline $26-34$ & 25.7 & 12.9 & 22.1 & 12.8 \\
\hline $35-54$ & 44 & 27.3 & 41.7 & 26.4 \\
\hline $55-64$ & 11.3 & 12.9 & 12.3 & 13 \\
\hline 65 or over & 5.1 & 14 & 7.7 & 14.7 \\
\hline \multicolumn{5}{|l|}{ Educational attainment $(\%)^{\mathrm{a}}$} \\
\hline Not a high school graduate & 5.9 & 16.5 & 5.1 & 15 \\
\hline High school graduate (includes equivalency) & 31.5 & 33.7 & 21.1 & 30 \\
\hline Some college-technical school or associate's & 36.6 & 28 & 37.5 & 29.7 \\
\hline Bachelor's degree & 16.2 & 12.9 & 22.3 & 16.2 \\
\hline Graduate or professional degree & 8.3 & 8.9 & 13.6 & 9.2 \\
\hline \multicolumn{5}{|l|}{ Household income $(\%)^{b}$} \\
\hline Below \$14,999 & 18 & 16.9 & 16.4 & 15.5 \\
\hline$\$ 15,000$ to $\$ 24,999$ & 12.1 & 13 & 9.1 & 12.7 \\
\hline$\$ 25,000$ to $\$ 49,999$ & 31.5 & 26 & 26.7 & 26.4 \\
\hline$\$ 50,000$ to $\$ 74,999$ & 17.2 & 17.6 & 17 & 18 \\
\hline$\$ 75,000$ to $\$ 99,999$ & 8.3 & 10.9 & 13 & 11.2 \\
\hline$\$ 100,000$ to $\$ 149,999$ & 6.3 & 10.1 & 7.1 & 10.4 \\
\hline Above $\$ 150,000$ & 2.2 & 5.3 & 5.4 & 6 \\
\hline
\end{tabular}

${ }^{\text {a }}$ State population is based on 25 years and over.

${ }^{b}$ In 2014 inflation-adjusted dollars.

Note: State population statistics are based on the 2012 American Community Survey 1-year estimates.

\section{Data}

Data were collected from a total of 1,011 respondents (505 from Kentucky and 506 from South Carolina). Qualtrics, a large online panel of general consumers, was contracted to distribute the survey. Specific information regarding the sampling process, such as response rate, is proprietary. Nevertheless, Table 2 provides selected sociodemographic statistics for the two states from the 2012 American Community Survey, as well as the sample demographics. Female respondents made up the majority of survey participants (about 69\%), but this makes intuitive sense when considering the female role in shopping behavior. For example, females resulted in $60 \%$ of the Fonner and Sylvia (2014) sample when analyzing WTP for seafood attributes. In order to proceed with the survey, participants had to respond "yes" to whether they classified themselves as the primary grocery shopper. Most survey respondents were between the ages of 35 and 54 (43\%). When asked about education, "some college, technical school, or associate's degree" was the majority response (37\%), and most respondents earned $\$ 50,000$ to $\$ 74,000(17 \%)$ annually. 


\section{Model}

Lancaster's (1966) formative study creates the framework to evaluate consumers' utility for products with an array of attributes. By recognizing that a collection of traits is significant, Lancaster (1966) proposed the theory of demand for products having one or more attributes.

When considering a number of $n$-choice situations and evaluating consumer $i$ 's selection of a product, McFadden's (1974) random utility theory can be applied. Consumer is indirect utility $\left(U_{i j n}\right)$ from selecting the $j$ th product in a group of $J$ products in the $n$th choice condition $(n=1,2$, $3, \ldots)$ is described as a linear function of product attributes $\left(X_{i j n}\right)$ by the following equation:

$$
U_{i j n}=\boldsymbol{X}_{i j n} \boldsymbol{\beta}+\varepsilon_{i j n}
$$

where $\boldsymbol{\beta}$ symbolizes a vector of indefinite marginal utilities from product attributes $\boldsymbol{X}_{i j n}$ of the alternate $j$ in choice situation $n$, and $\varepsilon_{i j n}$ denotes the random error term of the computed utilities. Assuming that consumers act rationally, utility is maximized through selecting alternatives $j$ in the $n$th choice framework (McFadden, 1974).

Owing to the extensive application of the conditional logit (CL) choice model for inference in discrete choice experiments, this econometric technique is applied as a baseline model in this research as well. By accepting that the independent and identical distribution (iid) of the error term $\left(\varepsilon_{i j n}\right)$ and independence of irrelevant alternatives (IIA) assumptions hold, the probability of the $j$ th option being selected can be modeled as follows:

$$
P\left(Y_{i n}=j\right)=\frac{\exp \left(\boldsymbol{X}_{i j n} \boldsymbol{\beta}\right)}{\sum_{j=1}^{J} \exp \left(\boldsymbol{X}_{i j n} \boldsymbol{\beta}\right)} \quad \text { For } j=1,2, \ldots J,
$$

where $Y_{i n}$ is an indicator variable representing the selection by consumer $i$ in the $n$th choice situation. Considering a closed-form probability function, the CL method can be assessed using maximum likelihood estimation (McFadden, 1974). Though straightforward to estimate, the IIA assumption is restrictive. Train (1998) developed an alternative to CL known as the mixed logit model. The mixed logit offers greater flexibility by relaxing the IIA assumption and incorporating preference heterogeneity, as well as accounting for correlations between multiple choice observations made by each respondent (Bliemer and Rose, 2010). This is also referred to as accounting for correlation in unobserved utility over repeated choices made by each respondent, or that the parameter estimates of the marginal utilities vary across respondents. The choice probability identified by the mixed logit is modeled as

$$
P\left(Y_{i n}=j\right)=\int \frac{\exp \left(\boldsymbol{X}_{i j n} \boldsymbol{\beta}\right)}{\sum_{(j=1)}^{J} \exp \left(\boldsymbol{X}_{i j n} \boldsymbol{\beta}\right)} f(\boldsymbol{\beta}) d \boldsymbol{\beta},
$$

where the coefficients in vector $\boldsymbol{\beta}$ are defined as random variables following density function $f$ as

$$
\beta_{i} \sim f\left(\beta_{0}, \boldsymbol{G}\right),
$$

with $\beta_{0}$ as the means of $\beta_{i}$ and $\boldsymbol{G}$ as the variance matrix. With the probability evaluated over a range of possible values of $\beta_{i}$ and the absence of a closed-form solution, the approach of approximating the likelihood function with simulated maximum likelihood is applied to the model (Train, 2009).

Following the estimation of $\boldsymbol{\beta}$ in either the conditional or mixed logit model, marginal WTP measures for an attribute $k$ is approximated as the coefficient estimate for the attribute divided by the negative marginal utility of price (Louviere, Hensher, and Swait, 2000):

$$
W T P_{k}=-\frac{\beta_{k}+\boldsymbol{\beta}_{k D} \times \boldsymbol{D}}{\beta_{\text {price }}}
$$

where $\boldsymbol{D}$ are covariates entered as interactions with the attributes in the logit model to further 
decompose the main effect of attribute $k$, and $\boldsymbol{\beta}_{\boldsymbol{k} \boldsymbol{d}}$ are the coefficients associated with the interaction effects. Thus, WTP measures the change in price associated with a unit increase in the respective attribute and approximates the monetary values of product attributes.

\section{Results}

The null hypothesis that the estimates are equivalent between the two samples was rejected by a joint F-test. As a result, data of the two states were estimated separately. Parameter estimation results for the mixed logit models are presented in Tables 3 and 4 for the Kentucky and South Carolina samples, respectively. A simulated maximum likelihood estimator with 1,000 Halton draws was utilized for the estimation.

For each state, the main effect utility parameter included coefficients for a series of dummy variables: Fresh (baseline is "previously frozen"), Local (baseline is "unlabeled"), BAP (baseline is "unlabeled"), CSF (baseline is "unlabeled"), HBH (baseline is "unlabeled"), and Price (four levels). The model formulations also included interaction effects. Specifically, the abovementioned main effects were interacted with the following variables: Age, Education level (Edu), Income (annual pretax income), ${ }^{2}$ Child (dummy variable indicating minors present in household), Employed (dummy variable indicating at least partially employed), Coast (dummy variable indicating growing up within 50 miles of a coast), and Identified (dummy variable indicating correctly answering true/false question). Other possible variables, such as whether a household had any direct family members with military service, were tested; however, these were not statistically significant in any formulation and thus were not included in the final model. Potential multicollinearity was checked by calculating the coefficient of correlation matrix of all variables used in the models; about $0.6 \%$ of the correlation coefficients were greater than 0.5 in absolute values. Readers are reminded of the possible minor multicollinearity. For the purpose of comparison, mixed logit model results incorporating only the main effects are reported in Appendix D. The result is highly consistent with the models including interactions.

Finally, a normal distribution was assumed for all main effect coefficients except the price. This is to avoid unrealistic WTP distributions associated with the ratio between two distributions (Carson and Czajkowski, 2019). The standard deviation of all random coefficients is presented alongside the corresponding main effect coefficients.

The variable "No choice" is a dummy variable indicating the third alternative in each choice set. It represents the opposite of the utility associated with the sum of the omitted levels for each attribute (Adamowicz et al., 1997), and as a result, its value depends on how each attribute is defined and entered into the model. In other words, it depends on the level omitted for each dummy variable. We focus on interpreting the coefficients associated with the attributes. Because the models presented in Tables 3 and 4 include interaction terms to further explain the main effects of the attributes, the coefficient estimates of the main effects cannot be explained alone. All interaction effects must be jointly considered, which is conducted when the WTP measures are calculated. Nevertheless, the standard deviation estimates of the main effects and the direction of the interaction effects can be explained. For both states, the standard deviation estimates of random coefficients for Fresh (Never Frozen), Local, and HBH are highly significant, suggesting a large degree of heterogeneity in consumer taste. Standard deviation estimates of the random coefficients BAP and CSF are not statistically significant.

For the Kentucky sample (Table 3), participant age has a negative impact on utility associated with the CSF attribute. This suggests that, holding all other factors constant, older consumers are

\footnotetext{
${ }^{2}$ The variables Age, Edu, and Income were obtained in the survey as cardinal categorical variables. These variables were subsequently converted to continuous variables before entering the models by taking the middle point of each respective category (the two end categories used the middle point spread of the adjacent category). This is mainly to reduce the number of interaction variables in the model while maintaining the cardinal nature of the data.
} 
Table 3. Mixed logit model estimation result—Kentucky sample

\begin{tabular}{|c|c|c|c|c|c|}
\hline Variable & Coefficient & Standard Error & Variable & Coefficient & Standard Error \\
\hline Main effect & & \multicolumn{4}{|c|}{ Standard deviation of main effect } \\
\hline No choice & -1.929 & 1.578 & No choice-SD & $3.347^{\star \star \star}$ & 0.210 \\
\hline Fresh & 0.253 & 0.551 & Fresh-SD & $1.001^{\star \star \star}$ & 0.102 \\
\hline Local & 0.460 & 0.468 & Local-SD & $0.937^{\star \star \star}$ & 0.078 \\
\hline BAP & $-0.779^{\star \star}$ & 0.363 & BAP-SD & 0.136 & 0100 \\
\hline CSF & 0.127 & 0.433 & CSF-SD & 0.026 & 0.115 \\
\hline $\mathrm{HBH}$ & $-0.772^{\star}$ & 0.457 & $\mathrm{HBH}-\mathrm{SD}$ & $0.542^{\star \star \star}$ & 0.103 \\
\hline Price & -0.034 & 0.064 & & & \\
\hline \multicolumn{6}{|l|}{ Interaction effect } \\
\hline Age* No choice & $0.039^{\star *}$ & 0.017 & Edu ${ }^{\star}$ No choice & $-0.300^{\star \star \star}$ & 0.109 \\
\hline Age*Fresh & 0.008 & 0.006 & Edu*Fresh & 0.041 & 0.038 \\
\hline Age*Local & 0.004 & 0.005 & Edu*Local & -0.016 & 0.032 \\
\hline Age ${ }^{\star} \mathrm{BAP}$ & 0.001 & 0.004 & Edu*BAP & $0.085^{\star \star \star}$ & 0.025 \\
\hline Age ${ }^{\star}$ SSF & $-0.009^{\star \star}$ & 0.005 & $\mathrm{Edu}^{\star} \mathrm{CSF}$ & 0.015 & 0.030 \\
\hline $\mathrm{Age}^{\star} \mathrm{HBH}$ & 0.000 & 0.005 & $\mathrm{Edu}{ }^{\star} \mathrm{HBH}$ & $0.61^{*}$ & 0.031 \\
\hline Age ${ }^{\star}$ Price & 0.000 & 0.001 & Edu*Price & $-0.015^{\star \star \star}$ & 0.004 \\
\hline Income ${ }^{\star}$ No choice & -0.049 & 0.064 & Child*No choice & $0.745^{\star}$ & 0.426 \\
\hline Income*Fresh & 0.004 & 0.023 & Child*Fresh & -0.025 & 0.150 \\
\hline Income*Local & 0.030 & 0.019 & ChildLocal & 0.141 & 0.126 \\
\hline Income ${ }^{\star}$ BAP & 0.018 & 0.015 & Child*BAP & 0.038 & 0.096 \\
\hline Income ${ }^{\star} \mathrm{CSF}$ & -0.014 & 0.018 & Child $^{\star}$ CSF & 0.028 & 0.115 \\
\hline Income* $\mathrm{HBH}$ & $0.035^{\star}$ & 0.019 & Child ${ }^{\star} \mathrm{HBH}$ & $0.329^{\star \star \star}$ & 0.122 \\
\hline Income*Price & -0.002 & 0.003 & Child ${ }^{\star}$ Price & $0.064^{\star \star \star}$ & 0.017 \\
\hline Employed ${ }^{\star}$ No choice & 0.544 & 0.445 & Coast ${ }^{\star}$ No choice & 0.312 & 0.623 \\
\hline Employed ${ }^{\star}$ Fresh & 0.011 & 0.165 & Coast ${ }^{\star}$ Fresh & -0.001 & 0.226 \\
\hline EmployedLocal & 0.170 & 0.139 & Coast*Local & $-0.566^{\star \star \star}$ & 0.194 \\
\hline Employed ${ }^{\star} B A P$ & -0.107 & 0.106 & CoastBAP & 0.056 & 0.145 \\
\hline Employed ${ }^{\star} \mathrm{CSF}$ & -0.096 & 0.127 & Coast $^{\star}$ CSF & 0.062 & 0.177 \\
\hline Employed ${ }^{\star} \mathrm{HBH}$ & -0.162 & 0.133 & Coast* ${ }^{*} \mathrm{BH}$ & -0.168 & 0.185 \\
\hline Employed ${ }^{\star}$ Price & $0.059^{\star \star \star}$ & 0.019 & Coast ${ }^{\star}$ Price & $0.060^{\star \star}$ & 0.026 \\
\hline Identified*BAP & 0.054 & 0.090 & & & \\
\hline Identified ${ }^{\star}$ CSF & 0.142 & 0.107 & $L L$ & -2924.05 & \\
\hline Identified $\mathrm{HBH}$ & $0.424^{\star \star \star}$ & 0.136 & Pseudo $R^{2}$ & 0.190 & \\
\hline
\end{tabular}

Notes: Asterisks $\left({ }^{\star},{ }^{\star \star}\right.$, and $\left.{ }^{\star \star \star}\right)$ indicate significance at the $10 \%, 5 \%$, and $1 \%$ level, respectively. BAP, Best Aquaculture Practices; CSF, Community-Supported Fishery; HBH, Homegrown by Heroes.

less likely to purchase CSF-labeled product. Education appears to affect consumer perception on several attributes. For the BAP and HBH labels, higher education leads to greater utility while also making consumers more price sensitive. Participant income strengthens the preference of the 
Table 4. Mixed logit model estimation result—South Carolina sample

\begin{tabular}{|c|c|c|c|c|c|}
\hline Variable & Coefficient & Standard Error & Variable & Coefficient & Standard Error \\
\hline \multicolumn{3}{|l|}{ Main effect } & \multicolumn{3}{|c|}{ Standard deviation of main effect } \\
\hline No choice & $-5.058^{\star \star \star}$ & 1.521 & No choice-SD & $2.882^{\star \star \star}$ & 0.196 \\
\hline Fresh & 0.078 & 0.576 & Fresh-SD & $1.157^{\star \star \star}$ & 0.102 \\
\hline Local & $-1.131^{\star \star \star}$ & 0.420 & Local-SD & $0.752^{\star \star \star}$ & 0.084 \\
\hline BAP & -0.017 & 0.352 & BAP-SD & 0.145 & 0.124 \\
\hline CSF & 0.421 & 0.417 & CSF-SD & 0.081 & 0.150 \\
\hline $\mathrm{HBH}$ & $-0.741^{\star}$ & 0.423 & $\mathrm{HBH}-\mathrm{SD}$ & $0.404^{\star \star \star}$ & 0.117 \\
\hline Price & $-0.157^{\star \star}$ & 0.064 & & & \\
\hline \multicolumn{6}{|l|}{ Interaction effect } \\
\hline Age*No choice & 0.009 & 0.016 & Edu*No choice & 0.066 & 0.101 \\
\hline Age*Fresh & 0.008 & 0.006 & EduFresh & 0.063 & 0.039 \\
\hline Age* Local & 0.003 & 0.005 & Edu*Local & $0.098^{\star \star \star}$ & 0.028 \\
\hline Age ${ }^{\star} B A P$ & -0.002 & 0.004 & Edu*BAP & $0.045^{\star}$ & 0.023 \\
\hline $\mathrm{Age}^{\star} \mathrm{CSF}$ & -0.006 & 0.004 & $\mathrm{Edu}{ }^{\star} \mathrm{CSF}$ & -0.032 & 0.028 \\
\hline Age* $\mathrm{HBH}$ & $0.011^{\star \star}$ & 0.005 & Edu*HBH & 0.045 & 0.028 \\
\hline Age ${ }^{\star}$ Price & -0.000 & 0.001 & Edu Price & -0.005 & 0.004 \\
\hline Income No choice & -0.066 & 0.052 & Child ${ }^{\star}$ No choice & -0.011 & 0.404 \\
\hline Income*Fresh & 0.025 & 0.021 & ChildFresh & -0.116 & 0.160 \\
\hline Income*Local & 0.009 & 0.015 & ChildLocal & $0.271^{\star \star}$ & 0.115 \\
\hline Income ${ }^{\star}$ BAP & -0.014 & 0.012 & Child ${ }^{\star}$ BAP & $0.200^{\star \star}$ & 0.096 \\
\hline Income ${ }^{\star} \mathrm{CSF}$ & 0.020 & 0.015 & Child $^{\star}$ CSF & 0.014 & 0.115 \\
\hline Income* $\mathrm{HBH}$ & -0.013 & 0.015 & Child $^{\star} \mathrm{HBH}$ & 0.123 & 0.116 \\
\hline Income ${ }^{\star}$ Price & 0.001 & 0.002 & Child ${ }^{\star}$ Price & 0.024 & 0.018 \\
\hline Employed ${ }^{\star}$ No choice & 0.379 & 0.444 & Coast ${ }^{\star}$ No choice & 0.584 & 0.433 \\
\hline Employed ${ }^{\star}$ Fresh & -0.049 & 0.170 & Coast ${ }^{\star}$ Fresh & 0.034 & 0.165 \\
\hline EmployedLocal & 0.099 & 0.121 & Coast*Local & -0.110 & 0.118 \\
\hline Employed ${ }^{\star}$ BAP & $-0.206^{\star *}$ & 0.101 & Coast ${ }^{\star} B A P$ & -0.120 & 0.098 \\
\hline Employed ${ }^{\star} \mathrm{CSF}$ & -0.053 & 0.121 & Coast $^{\star}$ CSF & -0.013 & 0.117 \\
\hline Employed ${ }^{\star} \mathrm{HBH}$ & $-0.206^{\star}$ & 0.122 & Coast $^{\star} \mathrm{HBH}$ & 0.029 & 0.118 \\
\hline Employed ${ }^{\star}$ Price & $0.059^{\star \star \star}$ & 0.019 & Coast ${ }^{\star}$ Price & $0.070^{\star \star \star}$ & 0.018 \\
\hline Identified ${ }^{\star}$ BAP & -0.046 & 0.089 & & & \\
\hline Identified ${ }^{\star}$ CSF & 0.068 & 0.107 & $L L$ & -3016.65 & \\
\hline Identified ${ }^{\star} \mathrm{HBH}$ & $0.418^{\star \star \star}$ & 0.129 & Pseudo $R^{2}$ & 0.176 & \\
\hline
\end{tabular}

Notes: Asterisks $\left({ }^{\star},{ }^{\star \star}\right.$, and $\left.{ }^{* \star \star}\right)$ indicate significance at the $10 \%, 5 \%$, and $1 \%$ level, respectively. BAP, Best Aquaculture Practices; CSF, Community-Supported Fishery; HBH, Homegrown by Heroes.

$\mathrm{HBH}$ attribute. Having at least one child living within the household makes consumers more in favor of the $\mathrm{HBH}$ attribute and not as sensitive to price. Participants with at least a part-time job are less sensitive to product price. Consumers growing up within 50 miles of the coast are less 
likely to purchase shrimp with "Kentucky Proud" (i.e., local) label and are less price sensitive. Answering the true or false question correctly is strongly and positively related to consumer utility associated with the $\mathrm{HBH}$ attribute. This suggests that consumers who understand the $\mathrm{HBH}$ label correctly have a higher value associated with the attribute. For all other attributes, there are no significant effects of answering the true or false questions correctly.

For the South Carolina sample (Table 4), participant age has a positive interaction effect with the $\mathrm{HBH}$ attribute, indicating older consumers are more likely to value the $\mathrm{HBH}$ attribute. Participants with higher education attainment place greater emphasis on Local as well as BAP. Although income does not seem to have a significant interaction effect with any product attribute, consumers with at least one child in the household are willing to pay more for products labeled Local and BAP. Compared with no employment, partial or full employment is associated with less WTP for BAP and HBH attributes, as well as less price sensitivity. Growing up within 50 miles of a coast has no effect on any attributes, only leading to less price sensitivity. Similar to the case for Kentucky, the $\mathrm{HBH}$ label was the sole significant attribute for significant and positive effects for participants answering the true or false question correctly.

Consumer preference is best reflected by WTP after considering all main and interaction effects jointly. Table 5 presents the WTP estimates following equation (4). All WTP standard deviations are estimated using the simulation approach described by Krinsky and Robb (1986) with 5,000 iterations. These standard deviation estimates reflect the standard errors in the mixed logit models. The focus and discussion pertained to the mean effects. At the top of the table, a list of sample means (median for discrete variables) is given for each variable used as a covariate interacting with the main effect attributes. When calculating WTP, all covariates are held at the sample mean $/ \mathrm{me}$ dian unless the interaction is at least significant at the $10 \%$ level in Table 3 or 4 . In this case, different values of the covariate variables are considered to show the WTP's impact.

First, the WTP for each attribute is calculated at the sample mean/median for each state. Comparing the two states, Kentucky consumers show more preference and WTP for Local, $\mathrm{BAP}$, and $\mathrm{HBH}$-labeled products. For Kentucky, the interacted terms for the attribute "Fresh (Never Frozen)" are all insignificant. As a result, the WTP of Kentucky consumers on shrimp that are fresh is measured at the sample mean, resulting in $\$ 6.33 / \mathrm{lb}$. compared with frozen while holding all other factors constant between these two product types. For the Kentucky Proud label, covariate variable "Coast" is significant. Thus, two consumer types are considered: participant A grew up within 50 miles of a coast, whereas participant B did not, as both have all other characteristics at the sample average. Participant B represents a sample average consumer as most of those sampled (i.e., did not grow up near a coast). Growing up near a coast has much less WTP for Local shrimp than the contrary. This is expected because Kentucky is an inland state; those who grew up near a coast are likely not originally from Kentucky. Residents with a profound coastal background are more likely to prefer products from that home state.

Following a similar logic, three levels of education are considered for the attribute BAP, while holding all other covariates at the sample average. WTP for the BAP attribute relative to products without the BAP attribute increases along with higher education. Among the lowest educated consumers, WTP is negative and suggests that consumers are not willing to pay anything for this attribute. On the other hand, consumers with the highest level of education are willing to pay as high as $\$ 3.27 / \mathrm{lb}$. for the BAP attribute; sample average education consumers are willing to pay $\$ 2.45 / \mathrm{lb}$.

Overall, CSF is not an attribute consumers prefer. However, consumer age significantly affects WTP for the CSF attribute. Despite variation in age, the WTP for CSF is largely negative compared with products not from a CSF. This reluctance in supporting CSF may be a reflection of consumer concern about the quality of products coming from a CSF because freshness is of high importance, as products not allocated to CSF shares may be perceived less fresh.

Sharply in contrast with CSF, the $\mathrm{HBH}$ attribute receives strong WTP across all consumer profiles. WTP for $\mathrm{HBH}$ at the sample average is $\$ 2.82 / \mathrm{lb}$. Highly educated or having at least 
Table 5. Willingness to pay (WTP) of different consumer profiles

\begin{tabular}{|c|c|c|c|c|c|}
\hline \multicolumn{3}{|c|}{$\begin{array}{l}\text { Kentucky Sample Mean/Median: } \text { Age }=40.60 ; \text { Edu }=13.75 \\
\text { Income }=47,959 ; \text { Child }=0 ; \text { Employed }=1 ; \text { Coast }=0 ; \\
\text { Identified }=1\end{array}$} & \multicolumn{3}{|c|}{$\begin{array}{l}\text { South Carolina Sample Mean/Median: } \\
\text { Age = 41.24; Edu = 14.33; Income = 56,726; } \\
\text { Child = 0; Employed = 1; Coast }=0 ; \text { Identified }=1\end{array}$} \\
\hline & WTP & Standard Error ${ }^{a}$ & & WTP & Standard Error ${ }^{a}$ \\
\hline Fresh & & & Fresh & & \\
\hline \multirow[t]{3}{*}{ Sample mean } & 6.33 & 3.45 & Sample mean & 7.53 & 3.76 \\
\hline & & & $E d u=6$ & 6.21 & 3.70 \\
\hline & & & $\mathrm{Edu}=18$ & 7.93 & 3.61 \\
\hline \multicolumn{2}{|c|}{ Local (Kentucky Proud) } & & \multicolumn{3}{|c|}{ Local (South Carolina Seafood) } \\
\hline Sample mean & 3.81 & 1.82 & Sample mean & 2.93 & 2.01 \\
\hline \multirow[t]{3}{*}{ Coast $^{b}=1$} & 1.07 & 0.39 & $E d u=6$ & -0.05 & 0.03 \\
\hline & & & $E d u=18$ & 6.45 & 3.33 \\
\hline & & & Child $=1$ & 5.03 & 2.86 \\
\hline BAP & & & BAP & & \\
\hline Sample mean & 2.45 & 1.88 & Sample mean & 1.51 & 0.82 \\
\hline$E d u=6$ & -3.10 & 1.33 & $E d u=6$ & -0.94 & 0.72 \\
\hline \multirow[t]{3}{*}{$E d u=18$} & 3.27 & 2.08 & $\mathrm{Edu}=18$ & 2.25 & 1.11 \\
\hline & & & Child $=1$ & 3.16 & 1.97 \\
\hline & & & Employed $=0$ & 2.03 & 1.04 \\
\hline CSF & & & CSF & & \\
\hline Sample mean & -0.35 & 0.22 & Sample mean & -0.52 & 0.36 \\
\hline Age $=21.5$ & 0.61 & 0.40 & & & \\
\hline Age $=65$ & -1.66 & 0.77 & & & \\
\hline $\mathrm{HBH}$ & & & $\mathrm{HBH}$ & & \\
\hline Sample mean & 2.82 & 1.72 & Sample mean & 2.68 & 1.61 \\
\hline Income $=15,000$ & 2.26 & 1.55 & Age $=21.5$ & 1.57 & 0.95 \\
\hline Income $=150,000$ & 4.33 & 2.19 & Age $=65$ & 3.82 & 1.90 \\
\hline $\mathrm{Edu}=6$ & 0.52 & 0.23 & Employed $=0$ & 2.88 & 1.25 \\
\hline$E d u=18$ & 3.10 & 2.94 & Identified $=0$ & 0.43 & 0.25 \\
\hline Child $=1$ & 6.99 & 4.91 & & & \\
\hline Identified $=0$ & 0.45 & 0.23 & & & \\
\hline
\end{tabular}

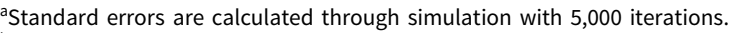

bWTP for each attribute measured at sample mean/median is displayed after "Sample mean" under each attribute. If some interactions are significant, WTPs are calculated under different values of the interactions. For instance, the only significant interaction for Local in the Kentucky sample is with variable Coast. As a result, although sample mean WTP reflects all variables held at sample mean/median, which suggests that Coast $=0$, because this interaction is significant, we also calculate the WTP when all other variables are held at sample mean/median, except that Coast $=1$ instead. The same applies to other attributes.

Note: BAP, Best Aquaculture Practices; CSF, Community-Supported Fishery; HBH, Homegrown by Heroes.

one child living in the household are more supportive to the label; the WTP for those with at least one child at home is as high as $\$ 6.99 / \mathrm{lb}$. Not understanding the $\mathrm{HBH}$ label (i.e., answered the true or false question incorrectly) leads to a great reduction in WTP measured at only $\$ 0.45 / \mathrm{lb}$. more compared with a non- $\mathrm{HBH}$ product, holding all other attributes common across products. 
Turning to South Carolina, education is a significant explanatory factor in consumer WTP for fresh shrimp, although the WTP does not change drastically across education. For Local, higher education favors this attribute along with having at least one child in the household. Consumer WTP for the BAP attribute is generally not high. Education (1), whether the household has at least one child at home (2), and employment status (3) are all significant determinants, and the WTP typically ranges from about $\$ 2$ to $\$ 3 / \mathrm{lb}$. for different consumer profiles. For the CSF attribute, like Kentucky consumers, the WTP is nearly nonexistent.

South Carolina consumers are also fond of the $\mathrm{HBH}$ attribute. In general, older consumers are more supportive. For consumers 65 and older, WTP is as high as $\$ 3.82 / \mathrm{lb}$. compared with non$\mathrm{HBH}$ shrimp. Employment status is statistically significant, but the corresponding WTP for HBH shrimp is not economically different regardless of whether the participant is employed or not. A large gap in WTP exists between whether a participant could correctly identify the truthfulness of a statement about the attribute. Greater understanding of the label is attributed to paying $\$ 2.68 / \mathrm{lb}$. more for $\mathrm{HBH}$ shrimp compared with $\$ 0.43 / \mathrm{lb}$. for those who do not understand the $\mathrm{HBH}$ product (signified by answering the true or false question incorrectly).

\section{Conclusion and implications}

By considering inland Kentucky and coastal South Carolina, we investigated consumer preferences for shrimp with multiple attributes. With a strong focus toward developing marketing strategies, the attributes examined were deemed possible candidates for producers and policy makers to adopt. By including unfamiliar, emerging, and hypothetical labels, we also contribute to the literature by establishing a foreground for further research.

Survey results had implications for both existing and developing attributes for the shrimp market. Consistent with previous studies, product form (i.e., "Fresh [Never Frozen]" or "Previously Frozen") produced the highest premium, with both states garnering this result. Criteria referring to product form may infer how customers evaluate quality such as taste, sight, and smell of the product, with results indicating a fresh form consisting of a higher quality versus a previously frozen product. Results showing some South Carolina residents willing to pay higher premiums could suggest living in a coastal state, with closer proximity and access to fresh products, may generate greater preference for nonfrozen products.

Concerning the popularity of the local food movement and support for producers operating within participants' state of residence, a "local" label allowed for analysis on preference for regional seafood. Although the literature is extensive, this study provided additional context of seafood labeling under which the "local" term was compared with other shrimp attributes. In both states, the "local" state labels generated the second highest premium behind product form, implying that support for shrimp sourced within the state is highly valued. Producers of aquaculture systems could use these results to justify labeling schemes indicating state origin, which ultimately may be more important than attributes such as environmental certification.

With the BAP label signifying environmental standards and sustainable practices, significant premiums resulted in both states, though not as strong as the product form and local attributes. Considering the relative magnitude of results, consumers may not fully understand nor value environmental stewardship as strongly in the case of aquaculture products. A possible explanation for this finding is that within aquaculture production systems, issues such as bycatch and stock (or supply) of certain seafood species is not as relevant as in ocean capture, so the value of certification may be limited. The only negative though insignificant product feature was the "Product of CSF" attribute. This could be the result of consumers' concerns regarding the quality of farm-raised seafood in a CSF context.

Consumer perception of veteran-sourced products has not been studied within the food literature. Despite the recent emergence of Homegrown by Heroes (as of 2013) and existence in today's food markets, the label was shown to be significant and produce a premium that was marginally 
less than "local" labels. Similar results between both states add to the importance of results. Policy makers may be encouraged to expand promotion and work with the Farmer Veteran Coalition to further develop and promote marketing programs for veterans in food production. Last, it is important to highlight that the WTP estimates are addable to each other. Thus, seafood producers can realize substantial premiums if their products include all the positive attributes.

For this study, we would like to mention limitations to better understand how future research can progress. First, the study includes two U.S. states located in the southeastern region; thus, it is hard to justify national implications. Although limiting our study to two states enables us to provide a more focused discussion on similarities and differences, future projects may survey a broader audience with greater sampling. Results can then be assessed from a national perspective, and more robust conclusions can be drawn on.

National scale is not the only market targeted when considering the global nature of the seafood market. A study of multiple consumers across various countries can support the understanding of international trade, as disputes considering the inflow of imported seafood products (e.g., shrimp) continue to affect domestic markets. An additional concern is the impact of wild-caught fisheries and environmental issues from a global scale, so consumer research in multiple countries could help understand preference in these areas.

Second, this study focuses only on the demand side of the market. Although it has been shown there is positive consumer support for many of the attributes considered, one must assess the feasibility of implementing these various labels by producers. With both mislabeling and transparency being prominent issues affecting the seafood supply chain, the supply side (or processing and distribution) must be considered, especially in strategizing marketing programs successfully. Future research may include developing producer surveys to analyze whether participation in certain programs would occur and if labels justify the economic investment to follow certain standards.

Third, the current analysis provides a snapshot of seafood consumption focusing on farm-raised shrimp. Certain participants who do not prefer shrimp or assess seafood attributes for other seafood species from a different perspective may affect conclusions made about certain labels. Studying other popular forms of seafood (e.g., salmon, tuna, etc.) could make conclusions more robust. A broader understanding of the overall consumption and, more important, long-term consumption trends is an interesting area for future research. Though many attributes included are emerging within the marketplace, one must also assess the sustainability of demand for future implementation.

Supplementary material. To view supplementary material for this article, please visit https://doi.org/10.1017/aae.2019.19

Acknowledgments. The authors would like to thank the anonymous reviewers for the beneficial feedback.

Financial support. This study is partially funded by Clemson University. Funding from the University of Kentucky and The Ohio State University is also appreciated.

Conflicts of interest. None.

\section{References}

Adamowicz, W., P. Boxall, M. Williams, and J. Louviere. “Stated Preference Approaches for Measuring Passive Use Values: Choice Experiments and Contingent Valuation.” American Journal of Agricultural Economics 80, 1(1998):64-75.

Adamowicz, W., J. Swait, P. Boxall, J. Louviere, and M. Williams. "Perceptions versus Objective Measures of Environmental Quality in Combined Revealed and Stated Preference Models of Environmental Valuation.” Journal of Environmental Economics and Management 32, 1(1997):65-84.

Adams, D.C., and A.E. Adams. "Availability, Attitudes and Willingness to Pay for Local Foods: Results of a Preliminary Survey." Paper presented at the American Agricultural Economics Association Annual Meeting, Orlando, FL, July 27-29, 2008.

Anderson, J.L., and S. Bettencourt. "A Conjoint Approach to Model Product Preferences: The New England Market for Fresh and Frozen Salmon.” Marine Resource Economics 8, 1(1993):31-49.

Andreatta, S., B. Nash, and G.B. Martin. "Carteret Catch: Raising Awareness of Local Seafood through Community and Business Partnerships.” Human Organization 70, 3(2011):279-88. 
Aquaculture Stewardship Council (ASC). “About the ASC.” Internet site: https://www.asc-aqua.org/about-us/about-the-asc/ (Accessed February 8, 2016).

Asche, F., M.F. Bellemare, C. Roheim, M.D. Smith, and S. Tveteras. "Fair Enough? Food Security and the International Trade of Seafood." World Development 67(March 2015):151-60.

Best Aquaculture Practices Certification. "Best Aquaculture Practices.” Internet site: Error! Hyperlink reference not valid. https://www.bapcertification.org/ (Accessed February 15, 2016).

Bliemer, M.C., and J.M. Rose. "Construction of Experimental Designs for Mixed Logit Models Allowing for Correlation across Choice Observations." Transportation Research Part B: Methodological 44, 6(2010):720-34.

Bonroy, O., and C. Constantatos. "On the Economics of Labels: How Their Introduction Affects the Function of Markets and the Welfare of All Participants." American Journal of Agricultural Economics 97, 1(2014):239-59.

Brinson, A., M. Lee, and B. Rountree. "Direct Marketing Strategies: The Rise of Community Supported Fishery Programs." Marine Policy 35, 4(2011):542-48.

Carlucci, D., G. Nocella, B.D. Devitiis, R. Viscecchia, F. Bimbo, and G. Nardone. "Consumer Purchasing Behaviour Towards Fish and Seafood Products. Patterns and Insights from a Sample of International Studies." Appetite 84, 1(2015):212-27.

Carson, R.T., and M. Czajkowski. "A New Baseline Model for Estimating Willingness to Pay from Discrete Choice Models." Journal of Environmental Economics and Management 95(May 2019):57-61.

Carson, R.T., J.J. Louviere, D.A. Anderson, P. Arabie, D.S. Bunch, D.A. Hensher, R.M. Johnson, et al. "Experimental Analysis of Choice." Marketing Letters 5, 4(1994):351-67.

Caswell, J.A., and E.M. Mojduszka. "Using Informational Labeling to Influence the Market for Quality in Food Products." American Journal of Agricultural Economics 78, 5(1996):1248-53.

Charles E., and J.P. Boude. "Enhancement Strategy, Artisanal Fishing Products and the Theory of Conventions." Presentation at the XIIIth European Association of Fisheries Economists (EAFE) Conference, Salerno, Italy, April 18-20, 2001.

Davidson, K., M. Pan, W. Hu, and D. Poerwanto. "Consumers' Willingness to Pay for Aquaculture Fish Products vs. Wild-Caught Seafood-A Case Study in Hawaii." Aquaculture Economics and Management 16, 2(2012):136-54.

Farmer Veteran Coalition. "Homegrown By Heroes." Internet site: https://www.farmvetco.org/hbh/ (Accessed November $18,2015)$.

Fonner, R., and G. Sylvia. "Willingness to Pay for Multiple Seafood Labels in a Niche Market." Marine Resource Economics 30, 1(2014):51-70.

Global Aquaculture Alliance (GAA). “BAP Certification.” Internet site: https://www.aquaculturealliance.org/what-we-do/ bap-certification/ (Accessed February 13, 2016).

Hanson, G.D., R.O. Herrmann, and J.W. Dunn. "Determinants of Seafood Purchase Behavior: Consumers, Restaurants, and Grocery Stores.” American Journal of Agricultural Economics 77, 5(1995):1301-5.

Holland, D., and C.R. Wessells. "Predicting Consumer Preferences for Fresh Salmon: The Influence of Safety Inspection and Production Method Attributes." Agricultural and Resource Economics Review 27, 1(1998):1-14.

Hu, W., T.A. Woods, and S. Bastin. "Consumers' Acceptance and Willingness to Pay for Blueberry Products with Nonconventional Attributes." Journal of Agricultural and Applied Economics 41, 1(2009):47-60.

Jacquet, J., D. Pauly, D. Ainley, S. Holt, P. Dayton, and J. Jackson. “Seafood Stewardship in Crisis." Nature 467(September 2010):28-29.

Jaffry, S., H. Pickering, Y. Ghulam, D. Whitmarsh, and P. Wattage. "Consumer Choices for Quality and Sustainability Labelled Seafood Products in the UK.” Food Policy 29, 3(2004):215-28.

Johnston, R.J., C.R. Wessells, H. Donath, and F. Asche. "Measuring Consumer Preferences for Ecolabeled Seafood: An International Comparison." Journal of Agricultural and Resource Economics 26, 1(2001):20-39.

Kentucky Department of Agriculture (KDA). "Comer Touts Homegrown by Heroes in Meeting with Joint Chiefs Officials." Press Release, March 10, 2015. Internet site: http://www.kyagr.com/Kentucky-AGNEWS/press-releases/Comer-toutsHomegrown-By-Heroes-in-meeting-with-Joint-Chiefs-officials.html (Accessed March 10, 2015).

Krinsky, I., and A. Robb. "On Approximating the Statistical Properties of Elasticities." Review of Economics and Statistics 68, 4(1986):715-19.

Kuchler, F., B. Krissoff, and D. Harvey. “Do Consumers Respond to Country-of-Origin Labelling?” Journal of Consumer Policy 33, 4(2010):323-37.

Lancaster, K.J. “A New Approach to Consumer Theory.” Journal of Political Economy 74, 2(1966):132-57.

Lim, K.H., W. Hu, L. Maynard, and E. Goddard. "U.S. Consumers' Preference and Willingness to Pay for Countryof-Origin-Labeled Beef Steak and Food Safety Enhancements." Canadian Journal of Agricultural Economics 61, 1(2013):93-118.

List, J.A., P. Sinha, and M.H. Taylor. "Using Choice Experiments to Value Non-Market Goods and Services: Evidence from Field Experiments." Advances in Economic Analysis and Policy 6, 2(2006):2.

Loureiro, M.L., and W.J. Umberger. "Estimating Consumer Willingness to Pay for Country-of-Origin Labeling." Journal of Agricultural and Resource Economics 28, 2(2003):287-301. 
Louviere, J.J., D.A. Hensher, and J.D. Swait. Stated Choice Methods: Analysis and Applications. New York: Cambridge University Press, 2000.

Low, S.A., A. Adalja, E. Beaulieu, N. Key, S. Martinez, A. Melton, A. Perez, et al. Trends in U.S. Local and Regional Food Systems: A Report to Congress. Washington, DC: U.S. Department of Agriculture, Economic Research Service, Administrative Publication No. 068, 2015.

Lowther, A., and M. Liddel, eds. Fisheries of the United States 2015. Silver Spring, MD: U.S. Department of Commerce, National Oceanic and Atmospheric Administration, National Marine Fisheries Service, 2015. Internet site: https:// www.fisheries.noaa.gov/resource/document/fisheries-united-states-2015-full-report (Accessed 2015).

Lusk, J., and J.A. Fox. "Value Elicitation in Retail and Laboratory Environments." Economics Letters 79, 1(2003):27-34.

Marsden, T., J. Banks, and G. Bristow. "Food Supply Chain Approaches: Exploring Their Role in Rural Development." Sociologia Ruralis 40, 4(2000):424-38.

McFadden, D. “Frontiers in Econometrics.” Conditional Logit Analysis of Qualitative Choice Behavior. P. Zarembka, ed. New York: Academic Press, 1974.

Merritt, M.G., K.L. DeLong, A.P. Griffith, and K.L. Jensen. "Consumer Willingness to Pay for Tennessee Certified Beef." Journal of Agricultural and Applied Economics 50, 2(2018):233-54. https://www.st.nmfs.noaa.gov/Assets/commercial/fus/ fus15/documents/FUS2015.pdf

Nganje, W.E., R.S. Hughner, and N.E. Lee. "State-Branded Programs and Consumer Preference for Locally Grown Produce.” Agricultural and Resource Economics Review 40, 1(2011):20-32.

O'Dierno, L.J., R. Govindasamy, V. Puduri, J.J. Myers, and S. Islam. Consumer Perceptions and Preferences for Organic Aquatic Products: Results from the Telephone Survey. New Brunswick, NJ: New Jersey Agricultural Experiment Station, Rutgers University, 2006.

Poerwanto, D. “Consumer Preference and Willingness to Pay for Fish Quality Characteristics: A Comparison across Species." Master's thesis, Department of Agricultural Economics, University of Kentucky, Lexington, 2011.

Quagrainie, K., S. Hart, and P. Brown. "Consumer Acceptance of Locally Grown Food: The Case of Indiana Aquaculture Products." Aquaculture Economics and Management 12, 1(2008):54-70.

Ratliff, E., M. Vassalos, and W. Hu. "What Factors Influence Consumer Preferences for Search and Credence Seafood Characteristics? An Empirical Analysis in Kentucky and South Carolina." Journal of Agricultural and Food Industrial Organization (2018). doi:10.1515/jafio-2018-0012.

Roheim, C.A., P.O. Sudhakaran, and C.A. Durham. "Certification of Shrimp and Salmon for Best Aquaculture Practices: Assessing Consumer Preferences in Rhode Island.” Aquaculture Economics and Management 16, 3(2012):266-86.

Rudd, M.A., N. Pelletier, and P. Tyedmers. "Preferences for Health and Environmental Attributes of Farmed Salmon amongst Southern Ontario Salmon Consumers." Aquaculture Economics and Management 15, 1(2011):18-45.

Silva, A., R.M. Nayga, B.L. Campbell, and J.L. Park. "Revisiting Cheap Talk with New Evidence from a Field Experiment." Journal of Agricultural and Resource Economics 36, 2(2011):280-91.

Smith, A., and J.B. MacKinnon. The 100-Mile Diet: A Year of Local Eating. Toronto: Random House Canada, 2007.

South Carolina Department of Agriculture. "Homegrown by Heroes.” Internet: https://agriculture.sc.gov/homegrown-byheroes-2 (Accessed October 2015).

Train, K.E. "Recreation Demand Models with Taste Variation." Land Economics 74, 2(1998):230-39.

Train, K.E. Discrete Choice Methods with Simulation. New York: Cambridge University Press, 2009.

U.S. Department of Agriculture (USDA). "USDA Announces Karis Gutter as USDA's First Military Veterans Agriculture Liaison.” Press Release No. 0252.14, November 14, 2014. Internet: https://www.usda.gov/media/press-releases/2014/11/14/ usda-announces-karis-gutter-usdas-first-military-veterans (Accessed January 2016).

U.S. Department of Agriculture, National Agricultural Statistics Service (USDA-NASS). "2013 Census of Aquaculture." September 29, 2014. Internet site: https://www.nass.usda.gov/Publications/AgCensus/2012/ (Accessed December 2015).

Wessells, C.R., R.J. Johnston, and H. Donath. "Assessing Consumer Preferences for Ecolabeled Seafood: The Influence of Species, Certifier, and Household Attributes.” American Journal of Agricultural Economics 81, 5(1999):1084-89.

Wessells, C.R., J. Kline, and J.G. Anderson. "Seafood Safety Perceptions and their Effects on Consumption Choices under Varying Information Treatments.” Agricultural and Resource Economics Review 25, 1(1996):12-21.

Whitmarsh, D., and M.G. Palmieri. "Social Acceptability of Marine Aquaculture: The Use of Survey-Based Methods for Eliciting Public and Stakeholder Preferences." Marine Policy 33, 3(2009):452-57.

Zhou, G., W. Hu, and W. Huang. "Are Consumers Willing to Pay More for Sustainable Products? A Study of Eco-Labeled Tuna Steak.” Sustainability 8, 5(2016):494.

Cite this article: Soley G, Hu W, and Vassalos M (2019). Willingness to Pay for Shrimp with Homegrown by Heroes, Community-Supported Fishery, Best Aquaculture Practices, or Local Attributes. Journal of Agricultural and Applied Economics 51, 606-621. https://doi.org/10.1017/aae.2019.19 